\title{
Passive Ultrasonic Irrigation in Endodontics: A Simple Innovative Technique
}

ISSN: 2637-7764

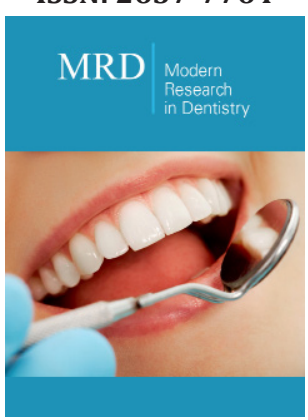

*Corresponding author: Tahir Yusuf Noorani, Conservative Dentistry Unit, School of Dental Sciences, Universiti Sains Malaysia, Health campus, 16150 Kubang Kerian, Kota bharu, Kelantan, Malaysia

Submission: 觜 December 03, 2019

Published: 㭗 December 16, 2019

Volume 4 - Issue 4

How to cite this article: Tahir $\mathrm{Yu}-$ suf Noorani, Passive Ultrasonic Irrigation in Endodontics: A Simple Innovative Technique. Mod Res Dent. 4(4). MRD.000595.2019.

DOI: 10.31031/MRD.2019.04.000595

Copyright@ Tahir Yusuf Noorani, This article is distributed under the terms of the Creative Commons Attribution 4.0 International License, which permits unrestricted use and redistribution provided that the original author and source are credited.

\section{Tahir Yusuf Noorani ${ }^{1,2 *}$}

${ }^{1}$ Conservative Dentistry Unit, School of Dental Sciences, Universiti Sains Malaysia, Health campus, 16150 Kubang Kerian, Kota bharu, Kelantan, Malaysia

${ }^{2}$ Conservative Dentistry Unit, Hospital Universiti Sains Malaysia, Health campus, 16150 Kubang Kerian, Kota bharu, Kelantan, Malaysia

\section{Introduction}

\section{Passive ultrasonic irrigation in endodontics}

During endodontic treatment is it is nearly impossible to completely clean the root canal system, using conventional endodontic instruments and techniques. This is mainly attributed to the complex anatomy of the root canal. Irrigants such as sodium hypochlorite facilitate the cleaning of the root canal system by its tissue dissolving and antibacterial activity. However, it is effective only when it is brought in contact with the pulp tissue and microorganisms within the root canal system. Passive ultrasonic irrigation is the term used to describe the transmission of acoustic energy from an oscillating K-file or smooth wire to an irrigant in the root canal [1]. Effectiveness of proprietary ultrasonic tips such as Irrisafe ultrasonic tip (Acteon, Merignac, France) or E1 Irrisonic insert (Helse Dental Technology, Brazil) for passive ultrasonic irrigation to improve the cleaning within the root canal system is well documented $[2,3]$. It is the authors opinion that similar cleaning efficacy can be achieved by using K-file and any conventional ultrasonic dental scaler (Figure 1). The authors believe that this technique is a relatively inexpensive way of carrying out passive ultrasonic irrigation to ensure complete and effective cleaning of the root canal system.

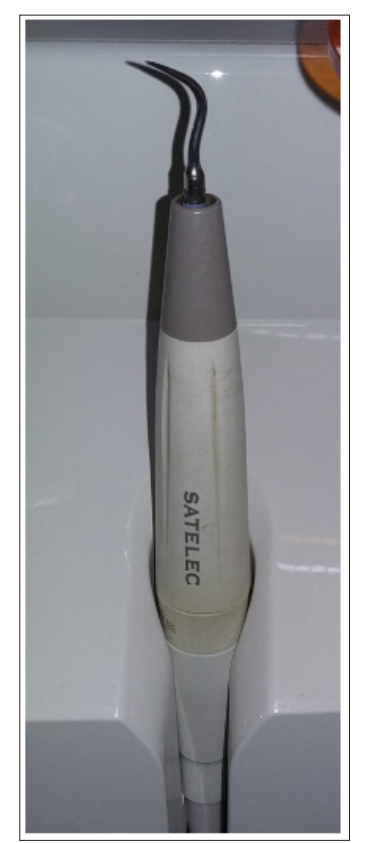

Figure 1: Ultrasonic dental scaler (Satelac, Acteon, France).

\section{The technique involves}

A. Achieving anesthesia for the tooth to be treated, isolation, followed by access cavity preparation. 
B. Determining the working length followed by cleaning and shaping of the root canals using either crown down or step back technique. Use of sodium hypochlorite as an irrigant during cleaning and shaping is recommended.
C. After completion of cleaning and shaping, the root canals are irrigated with $2.5 \%$ sodium hypochlorite solution (Figure 2).

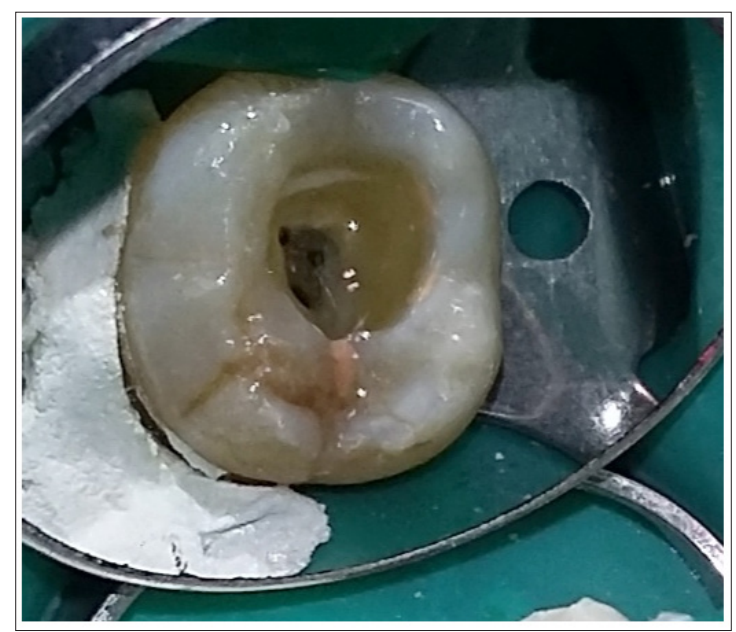

Figure 2: Tooth LR7 undergoing root canal treatment. The root canals and pulp chamber flushed with 2.5 sodium hypochlorite solution (HUSM pharmacy, Malaysia).

D. A size 15K-file is inserted into the root canal $1 \mathrm{~mm}$ short of root canal (Figure 3) to transmit the ultrasonic energy to the K-file the working length. Ultrasonic dental scaler is activated and its tip is brought in contact with the shank of the K-file inserted into the and in-turn to the irrigant present within the root canal system.

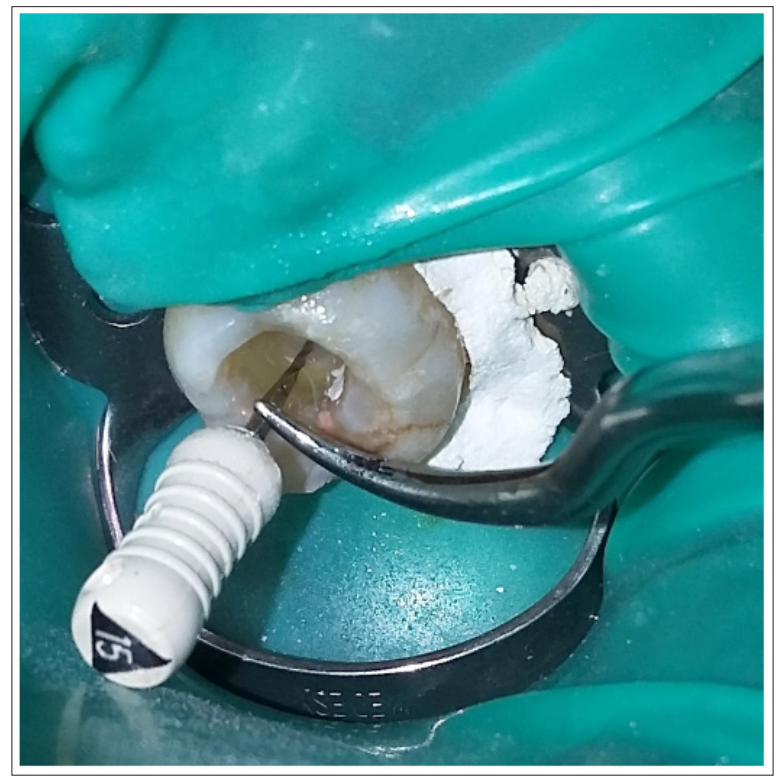

Figure 3: A size 15K file (Dentsply, UK) inserted into the root canal and an activated ultrasonic tip brought in contact with the shank of the $\mathrm{K}$ file to carry out passive ultrasonic irrigation.

E. Passive ultrasonic irrigation as mentioned in step 4 is carried out for up to 1 minute for each root canal.

F. Final irrigation with EDTA solution and completion of the root canal treatment with obturation and appropriate coronal restoration.

\section{Acknowledgement}

Financial support from USM short term grant no. 304/ PPSG/6315195 is highly acknowledged. Support from management of Hospital Universiti Sains Malaysia is also acknowledged. 


\section{References}

1. Van der Sluis LW, Versluis M, Wu MK, Wesselink PR (2007) Passive ultrasonic irrigation of the root canal: a review of the literature. International Endodontic Journal 40(6): 415-426.

2. Vivan RR, Duque JA, Alcalde MP, So MV, Bramante CM, et al. (2016)
Evaluation of different passive ultrasonic irrigation protocols on the removal of dentinal debris from Artificial Grooves. Brazilian Dental Journal 27(5): 568-572.

3. Mozo S, Llena C, Chieffi N, Forner L, Ferrari M (2014) Effectiveness of passive ultrasonic irrigation in improving elimination of smear layer and opening dentinal tubules. J Clin Exp Dent 6(1): e47-52. 